\title{
Current options for the treatment of Paget's disease of the bone
}

\author{
Daniela Merlotti \\ Luigi Gennari \\ Giuseppe Martini \\ Ranuccio Nuti \\ Department of Internal Medicine, \\ Endocrine-Metabolic Sciences \\ and Biochemistry, University \\ of Siena, Siena, Italy
}

This article was published in the following Dove Press journal:

Open Access Rheumatology Research and Reviews

17 July 2009

Number of times this article has been viewed

\begin{abstract}
Paget's disease of bone (PDB) is a chronic bone remodelling disorder characterized by increased osteoclast-mediated bone resorption, with subsequent compensatory increases in new bone formation, resulting in a disorganized mosaic of woven and lamellar bone at affected skeletal sites. This disease is most often asymptomatic but can be associated with bone pain or deformity, fractures, secondary arthritis, neurological complications, deafness, contributing to substantial morbidity and reduced quality of life. Neoplastic degeneration of pagetic bone is a relatively rare event, occurring with an incidence of less than $1 \%$, but has a grave prognosis. Specific therapy for PDB is aimed at decreasing the abnormal bone turnover and bisphosphonates are currently considered the treatment of choice. These treatments are associated with a reduction in plasma alkaline phosphatase (ALP) activity and an improvement in radiological and scintigraphic appearance and with a reduction in bone pain and bone deformity, Recently, the availability of newer, more potent nitrogen-containing bisphosphonates has improved treatment outcomes, allowing a more effective and convenient management of this debilitating disorder.
\end{abstract}

Keywords: Paget's disease of bone, bisphosphonates, aminobisphosphonates, bone remodeling

\section{Introduction}

Paget's disease of bone (PDB) is a chronic disorder which typically results in enlarged and deformed bones in one or more regions of the skeleton. ${ }^{1,2}$ Excessive bone breakdown and formation can cause the bone to weaken. As a result, bone pain, arthritis, noticeable deformities and fractures can occur. It affects both males and females, with a slight predominance in males. PDB is most common in white people of European descent, but it also occurs in blacks, whereas it is rare in people of Asian descent. ${ }^{3-5}$ Clinical, radiological, and necropsy data from different countries suggests pronounced geographical variations in the prevalence of the disease, with highest prevalence rates in Britain, and other countries with high rates of immigration of people of British descent in the 19th and 20th centuries., ${ }^{3,5}$ A recent UK study in large cohort from the General Practice Research Database indicated over the period 1988 to 1999 an incidence rate of clinically diagnosed PDB of 5 per 10,000 person-years among men and 3 per 10,000 person-years among women 75 years of age. ${ }^{6}$ Several studies of the secular trends in PDB suggest declining rates in both prevalence and severity at diagnosis. $^{7-9}$

The cause of PDB remains in large part unknown. Research findings suggest that the disorder may be caused by a slow-acting viral infection of bone, a condition which
Correspondence: Daniela Merlott Department of Internal Medicine, Endocrine-Metabolic Sciences and Biochemistry, University of Siena,Viale Bracci I, 53100 Siena, Italy Tel +39577 585364

Fax +39 577233446 ; +39 577233480

Email merlotti4@unisi.it; dmerlotti@yahoo.it 
is present for many years before symptoms appear. There are also data supporting a hereditary hypothesis, since the disease may appear in more than one member of a family, and mutations in different genes have been recently associated to classical PDB or PDB-related disorders. Current evidence suggests that both environmental and genetic factors are involved in classical PDB. How the virus and the genetic factors are intertwined in PDB pathogenesis is not yet clear. Genetic factors may increase the individual chance of getting the disease, and mutations in the SQSTM1 gene have been described in sporadic and familial PDB patients. ${ }^{10}$ Individuals with a genetic predisposition to PDB may be more susceptible to develop the disorder after exposure to a viral infection. Another potential explanation is that the genetic version of the disease represents only one group of PDB patients and that the other patients have a type of PDB that originates from viral exposure or other unknown factors. Moreover, recent studies have found that SQSTM1 mutants have enhanced bone resorption and this could provide some mechanistic understanding of the efficacy of anti-resorptive compounds for the treatment of PDB. ${ }^{11,12}$

The characteristic feature of the disease is an increased resorption followed by an increase in bone formation. Generally the evolution of the disease follows three major phases. In the early phase, termed "osteolytic phase" bone resorption predominates and there is a concomitant increased vascularity of involved bones. Commonly the excessive resorption of pagetic bone by osteoclasts is followed closely by formation of new bone. During this second phase of the disease ("osteoblastic phase") the new bone that is made is structurally abnormal, presumably because of the accelerated nature of the remodeling process. Newly deposed collagen fibers are laid down in a disorganized rather than a linear fashion, creating the so called "woven bone". With the time, the hypercellularity at the affected bone may diminish leading to development of a sclerotic, less vascular pagetic mosaic without evidence of active bone turnover. This is the so-called "sclerotic" or "burned-out" phase of PDB. Typically all these three phases of the disease can be seen at the same time at different sites in a single pagetic patient.

Pain, and namely localized bone pain, is the most common symptom that brings a patient with PDB to a physician. Pain varies greatly from patient to patient depending on the location and extent of the disease. It may arise from increased vascularity, from distortion of the periosteum due to disorganized remodeling, or from a focus of mechanical stress. Alternatively, another source of pain may be from irritation of nerves supplying affected bones. However, many patients who have PDB do not know they have it, since the disease may be so mild that is not symptomatic. Moreover, the symptoms are often confused with arthritis or other skeletal disorders. Sometimes, the physician is alerted to the possibility of PDB when physical deformities appears (ie, enlargement of the skull or bowing of the tibia) or when a blood test reveals an elevated level of bone turnover markers. In most cases, the diagnosis of PDB is made only after complications have developed. These complications mainly include osteoarthritis, fractures, severe bone deformity, neurological syndromes and, rarely, osteosarcoma, which significantly affect the morbidity and reduce the quality of life of patients. Osteoarthritis is common, affecting up to $50 \%$ of patients with PDB and can be quite painful. ${ }^{6,13}$ A variety of disturbances and neurological syndromes can be associated with PDB of the skull and spinal column as result of pressure on the brain, spinal cord or nerves by enlarged pagetic bones. ${ }^{12}$ Irreversible hearing loss can occur in $13 \%$ of patients. ${ }^{14}$ Bowing of weight bearing bones is another common feature of PDB. ${ }^{15}$ It occurs most commonly in the femur and tibia. These types of deformities are often associated with stress fractures on the convex surface of the bowed bone. Pathologic fractures may occur at any stage even though are more common in the lytic phase of the disease (Figure 1). Blood flow may be markedly increased in extremities involved with PDB, leading in some instances to high-output heart failure. There are also reports suggesting an increased incidence of calcific aortic disease or other valve calcifications. ${ }^{6,13,16}$ One of the most serious complications of PDB is neoplastic degeneration of pagetic bone with an increased incidence of sarcomas, especially in polyostotic cases of the disease. The majority of these tumors are classified as osteosarcomas, although fibrosarcomas and condrosarcomas may be also seen. Approximately $0.5 \%$ to $1 \%$ of pagetic patients develop osteosarcoma, an increase in the risk that is several thousand-fold higher than in the general population. It has been estimated that $20 \%$ of the patients with osteosarcoma over the age of 60 have PDB as a predisposing condition. ${ }^{17}$ This significantly contributes to the mortality and morbility of PDB patients. The sarcomas most frequently arise in the femur, tibia, humerus, skull, mandibula, and pelvis but rarely occur in vertebrae. Death from massive local extension or from pulmonary metastases occurs in the majority of cases in 1 to 3 years. Benign giant-cell tumor also may occur in pagetic bone. ${ }^{18}$ Radiographic and eventually histological appraisal of new lesions is essential in the diagnosis, as patients in this age group are also at increased risk of developing other diseases or bone metastases. 


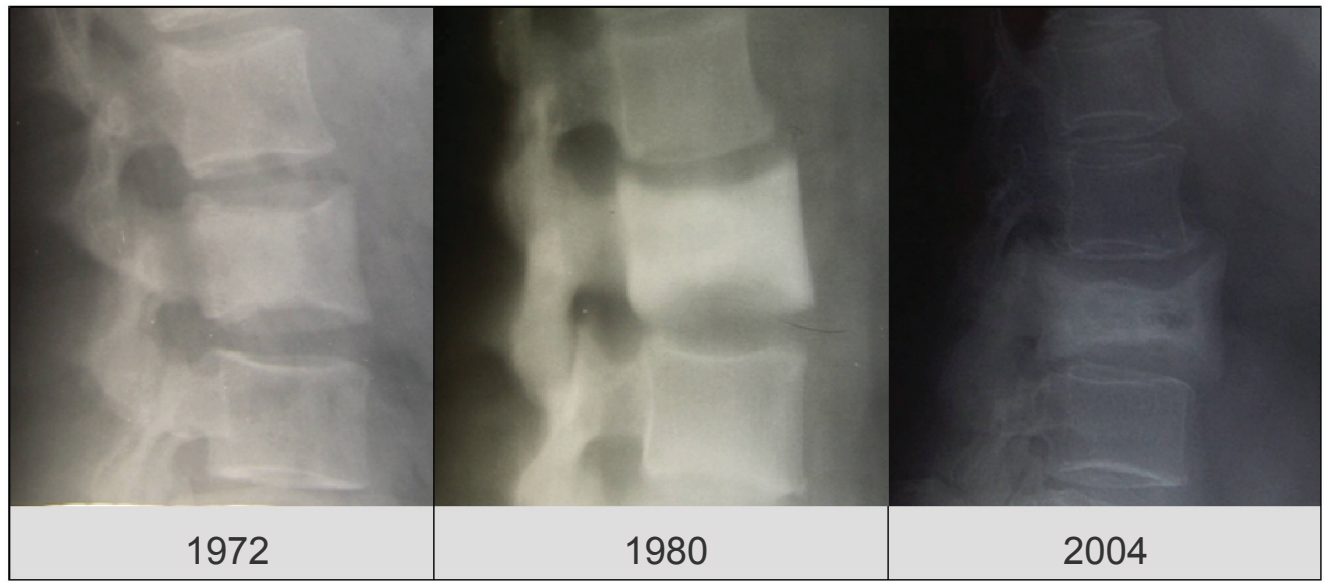

Figure I Fracture of a pagetic vertebra occurring in an untreated patient. The presence of Paget's disease of the bone was evident in the lumbar $\mathrm{x}$-ray performed in 1972 and 1980 .

\section{Indications for treatment in PDB}

The primary goal of PDB treatment is to restore normal bone turnover in order to relieve symptoms such as bone pain and prevent complications that result from the abnormal resorption and overgrowth of pagetic bone (Table 1). Treatment can be also indicated for PDB patients with orthopedic complications, undergoing elective surgery at affected bone sites. In this case the normalization of bone turnover is able to reduce blood flow in pagetic bone and thus decrease blood loss during surgery. In elderly polyostotic patients with advanced disease, treatment is also indicated for the management of immobilization hypercalcemia. However, almost any patient (particularly those with the involvement of the skull, weight bearing bones, and bones adjacent to major joints) may benefit from antiresorptive treatment, even if there are no symptoms, because of the potential to reduce disease progression, bone deformity and related complications. Indeed, even though it has not been proven conclusively that restoring normal bone turnover effectively reduces the risk of later complications, in untreated PDB the progression

Table I Indications for treatment of Paget's disease of bone

- Any symptom that is caused by metabolically active Paget's disease (ie, bone pain)

- Involvement of pagetic sites at high risk for complications (even in absence of symptoms):

a) Weight-bearing bones

b) Skull and/or spine

c) Bone adjacent to major joints such as hip or knee

- Planned surgery at a metabolically active pagetic site

- Immobilization (leading to hypercalcemia) of disease usually occurs with extension of osteolitytic changes and bone deformity. ${ }^{19}$ Conversely, suppression of bone turnover with antiresorptive therapy is associated with normal lamellar patterns of new bone deposition as seen on bone biopsy specimens, ${ }^{20}$ and there are isolated case reports showing improvement of deformity or hearing loss after treatment. ${ }^{21,22}$ A long-term preliminary observation of 41 PDB patients who received multiple bisphosphonate courses for an average of 12 years evidenced an increased prevalence of complications in patients whose bone turnover marker levels were lowered but not normalized. ${ }^{20}$

\section{Treatment options for PDB}

Since in PDB the increased activity of osteoclasts leading to increased bone resorption remains coupled to a parallel increase in osteoblast activity and bone formation, it is sufficient to treat the osteoclast to restore bone-remodeling rates towards normal. Currently, all agents used to treat PDB are antiresorptive in nature, and include calcitonin and bisphosphonates (Table 2). Even though antiresorptive therapy may reduce bone pain, symptomatic treatment with non-steroidal anti-inflammatory compounds could be required in some patients to further reduce bone pain due to osteoarthritis or nerve compression. In these circumstances, patients may also respond to opioid analgesics, acupuncture, electrical nerve stimulation or the use of walking aids. ${ }^{23}$ Moreover, since new bone formation usually occurs during treatment in order to repair pagetic bone, and since hypocalcemia and hyperparathyroidism are common after the suppression of bone turnover, daily supplements of calcium and vitamin $\mathrm{D}$ should be also recommended to PDB patients in addition to antiresorptive therapy. 
Table 2 Therapeutic agents for Paget's disease of bone and major treatment regimens

\begin{tabular}{ll}
\hline Compound & Dose \\
\hline Calcitonin & $50-100 \mathrm{U} /$ day subcutaneously or 3 times a \\
& week for $6-18$ months \\
Etidronate & $400 \mathrm{mg} /$ day for 3 months \\
Tiludronate & $400 \mathrm{mg} /$ day for 3 months \\
Clodronate & $400-1600 \mathrm{mg} /$ day orally for $3-6$ months or \\
& $300 \mathrm{mg} /$ day intravenously for 5 days \\
Pamidronate & $30-60 \mathrm{mg} /$ day intravenously for 3 days \\
Alendronate & $40 \mathrm{mg} /$ day for 6 months \\
Risedronate & $30 \mathrm{mg} /$ day for 2 months \\
Zoledronate & $5 \mathrm{mg}$ intravenously by a single infusion \\
Neridronate & $200 \mathrm{mg}$ intravenously by a single infusion on \\
& 2 consecutive days \\
\hline
\end{tabular}

Even though calcitonin and different compounds (ie, mithramycin and gallium nitrate) have been successfully used to treat PDB over past years, bisphosphonates are currently considered the treatment of choice. ${ }^{23,24}$

\section{Calcitonins}

Calcitonin was the first antiresorptive agent to be used for PDB (generally at daily subcutaneous injections for several months) and is still approved for the treatment of PDB. The synthetic polypeptide hormone of salmon calcitonin is available therapeutically as a formulation for parenteral administration, injected subcutaneously or intramuscularly. The usual starting dose is $100 \mathrm{U}$, subcutaneously, initially on a daily basis. Symptomatic benefit may be apparent in a few weeks, and the biochemical benefit (typically about a $50 \%$ reduction from baseline in serum alkaline phosphatase) is usually seen after 3 to 6 months of treatment. After this period, many clinicians reduce the dose to 50 to $100 \mathrm{U}$ every other day or three times weekly. This agent has been associated with normalization of alkaline phosphatase or symptom relief in up to $50 \%$ of patients, ${ }^{24}$ but is generally less effective than the more potent bisphosphonates, has a short-term action on bone, and resistance to treatment can develop after different treatment courses. The main side effects of parenteral salmon calcitonin include flush, nausea, vomiting, diarrhea and pain at the site of injection. Symptomatic hypocalcemia is exceptional, as well as hypersensitivity to the compound.

The recently developed intranasal calcitonin seems to have a lower incidence of the side effects described for parental formulations. ${ }^{25}$ The optimal dose in Paget's disease with intranasal formulation is not known, even though anecdotal evidence suggests that, in occasional patients with mild disease, the 200-U single spray dose given daily may lower biochemical indices and relieve mild symptoms, such as increased warmth in a pagetic tibia. However intranasal calcitonin is not specifically approved for use in PDB.

Given the effectiveness of bisphosphonates, the use of calcitonin in PDB should possibly be reserved for the few patients with contraindications to bisphosphonates.

\section{Bisphosphonates}

Bisphosphonates are the treatment of choice of patients with PDB, as well as of many other conditions characterized by increased bone turnover such as osteoporosis and bone metastases.

These compounds are synthetic analogues of pyrophosphate that bind to hydroxyapatite in bone.

In bisphosphonates, the oxygen molecule that binds the two phosphate molecules of pyrophosphate (P-O-P) is substituted by a carbon (P-C-P). This substitution renders bisphosphonates resistant to biological degradation and therefore suitable for clinical use.

The physicochemical effects of many of the bisphosphonates are very similar to those of pyrophosphate..$^{26,27}$ Thus, they inhibit the formation, delay the aggregation, and also slow down the dissolution of calcium phosphate crystals. All these effects are related to the marked affinity of these compounds for solid-phase calcium phosphate, on the surface of which they bind strongly. However, bisphosphonates not only inhibit the growth and dissolution of calcium crystals but had also another action relevant to clinical practice, namely, they have particularly high affinity for areas of high bone turnover and inhibit osteoclast activity. Both these properties render them particularly effective in the treatment of PDB. In fact, they are much more potent antiresorptives than calcitonin, and their effects on bone turnover may persist after therapy discontinuation for months or even years.

This class of antiresorptive agents include several compounds that differs for the R1 (the bone hook) and/or R2 (the bioactive moiety) side chains that are attached to the central (geminal) carbon atom and that are not present in pyrophosphate (Figure 2). All the currently used bisphosphonates share common pharmacological properties such as selective skeletal uptake and binding to hydroxyapatite crystals, suppression of osteoclast-mediated bone resorption, long time retention in the skeleton and unmetabolized urinary excretion. However, differences in phosphonate groups with R1 are responsible for selective targeting and binding of bisphosphonates to bone, while the structure of 


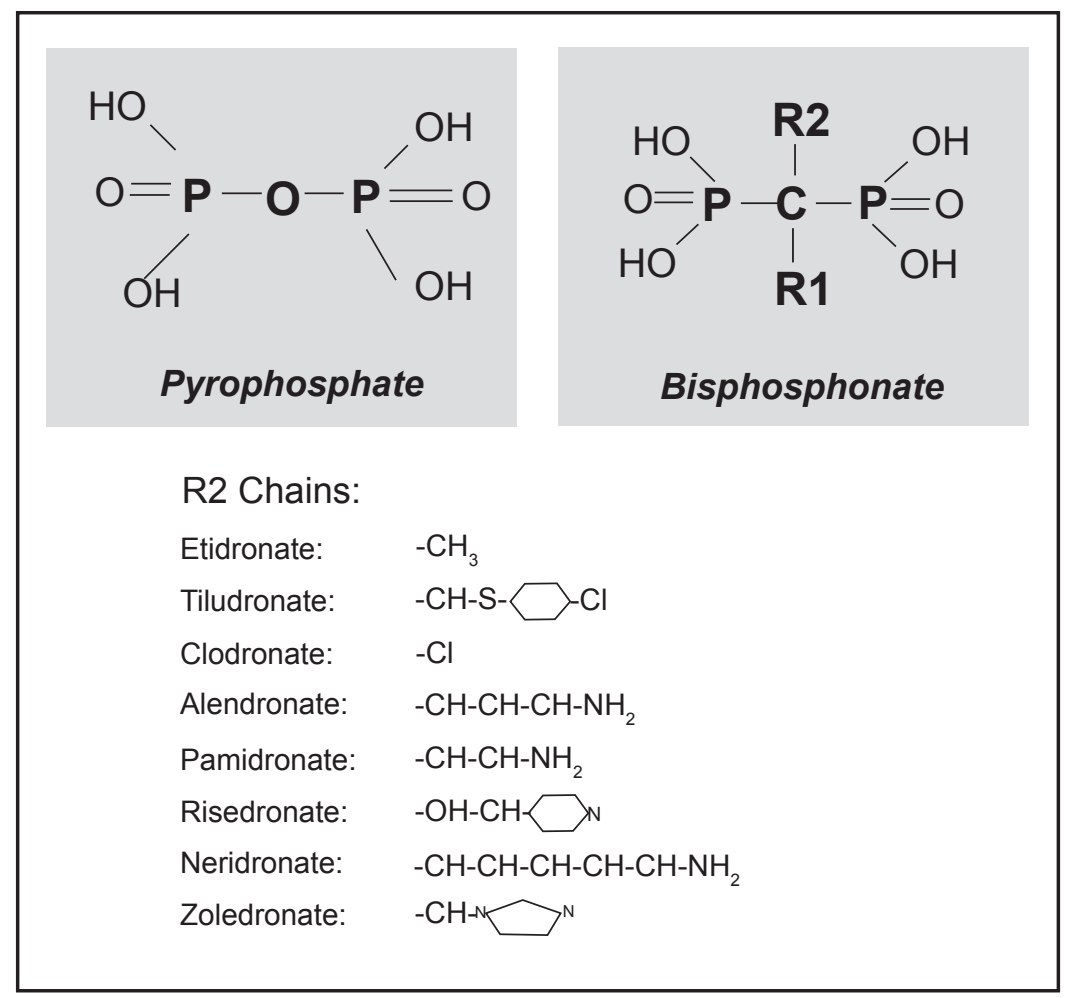

Figure 2 Chemical structure of pyrophosphate and geminal structure of bisphosphonates with functional RI (bone hook) and R2 (the bioactive moiety) domains. The structure of the R2 side chains of the major bisphosphonates (responsible for their potency and their action on bone resorption) are indicated in the lower panel.

the $\mathrm{R} 2$ is responsible for their potency and their action on bone resorption. ${ }^{26}$

Numerous studies have demonstrated the efficacy of bisphosphonates in the management of patients with PDB. With the first generation bisphosphonates such as etidronate and tiludronate there was only a 10 - to 100 -fold difference between doses that inhibit mineralization compared with doses that reduce bone resorption. ${ }^{27}$ Enhancing this window was readily achieved and more potent bisphosphonates have been developed and superseded etidronate or tiludronate in the treatment of PDB. All these bisphosphonates are characterized by the presence of a basic primary nitrogen atom in the R2 side chain and are called amino-bisphosphonates. These include alendronate, risedronate, pamidronate, neridronate, and, most recently, zoledronic acid.

\section{Nonamino bisphosphonates}

Historically, etidronate was the first bisphosphonate to be used in the treatment of PDB. At an oral daily dose of $400 \mathrm{mg}$ for 6 months, with at least a 6-month drug-free interval without retreatment, etidronate was associated with about $50 \%$ reductions in levels of serum alkaline phosphatase, the bone formation marker that is most commonly used to monitor the effects of treatment on bone turnover.
However, because of its modest antiresorptive potency and inhibition of bone formation leading to a narrow therapeutic window, treatment effects were transient and failure was not uncommon. ${ }^{28-31}$ Moreover a consistent portion of patients tended to become resistant. ${ }^{30,32}$ Greater reductions in bone turnover were achieved with higher etidronate doses, but this is contraindicated because prolonged use or doses higher than $5 \mathrm{mg} / \mathrm{kg}$ /day can induce osteomalacia..$^{29,30}$

Tiludronate showed a slight increased efficacy with the respect to etidronate at the dose of $400 \mathrm{mg}$ daily for 6 months. In a pivotal US trial, this agent was able to normalize serum alkaline phosphatase levels in $35 \%$ of patients, ${ }^{33}$ compared to $15 \%$ to $17 \%$ observed in etidronate trials. With tiludronate the likelihood of a mineralization problem was largely eliminated. ${ }^{33}$

Clodronate (clodronic acid, dichloromethylene bisphosphonate) is a bisphosphonate which has demonstrated efficacy in patients with a variety of diseases of enhanced bone resorption including PDB, hypercalcemia of malignancy and osteolytic bone metastases. In addition, early reports demonstrated potential efficacy of clodronate in the treatment of osteoporosis. Several studies demonstrated that longer courses of clodronate given orally (usually $1600 \mathrm{mg} /$ day for 6 months) effectively reduced bone pain 
and/or improved mobility in most patients with PDB, and these effects persisted for up to 12 months after discontinuing clodronate. ${ }^{34}$ Since the response to $<400 \mathrm{mg}$ oral clodronate appears to be incomplete and relapse occurs more rapidly than with higher doses most studies in PDB used oral doses between 400 and $3200 \mathrm{mg} /$ day. ${ }^{35-37}$ Some studies indicated that there is relatively little difference in the degree of disease suppression achieved with doses between 800 and $1600 \mathrm{mg}$ daily given for 3 to 6 months, ${ }^{36}$ but the duration of remission appears to be longer with the higher doses. ${ }^{38}$ In addition, the magnitude of the response and its duration depend on the duration of treatment and the total dose administered, so that several months of treatment with oral clodronate are usually required when a durable response is desired. ${ }^{39}$ Clodronate is also available for intramuscular or short term intravenous administration. Intravenous regimens of $300 \mathrm{mg} /$ day for 5 days demonstrated to suppress disease activity in PDB patients with no significant differences between different regimens of administration. ${ }^{39}$

\section{Amino-bisphosphonates}

Different aminobisphosphonates are currently available for PDB with different oral and intravenous dosing regimens.

Alendronate sodium is approved for the treatment of PDB at a dose of $40 \mathrm{mg}$ /day for 6 months. At this treatment regimen, this compound was generally well tolerated and was effective in suppressing disease activity and improving lytic bone lesions on radiographs in most patients with PDB..$^{40-42}$ A majority of subjects in clinical trials $(>70 \%)$ achieved normalization of total alkaline phosphatase (ALP) levels after a 6-mo course, and many of these remained in biochemical remission for the next 12 to 18 months. ${ }^{34}$ Recently, a weekly dose of $280 \mathrm{mg}$ (seven times the daily $40 \mathrm{mg}$ dose) has been tested in PDB. Preclinical studies indicated that this dose is unlikely to pose significant safety concerns if dosed in a solution at neutral $\mathrm{pH}$, and the oral weekly dosing may have the potential for better upper gastro-intestinal safety and tolerability. ${ }^{43,44}$ However, despite a similar efficacy, the $280 \mathrm{mg}$ weekly dosage formulation seems to be less well tolerated than the $40 \mathrm{mg} /$ day tablet. Both treatment regimens showed a similar incidence of non-serious adverse experiences, but more patients in the alendronate $280 \mathrm{mg} /$ week group discontinued therapy due to adverse events. ${ }^{45}$ Another oral amino-bisphosphonate, risedronate, is available for PDB at a daily dose of $30 \mathrm{mg}$ for 2 months. In the pivotal clinical trial, $80 \%$ of the patients achieved a normal ALP level 6 months after initiation of treatment, with a period of subsequent disease suppression (18 months) similar to that achieved with alendronate or pamidronate. ${ }^{46}$ Both alendronate and risedronate have been extensively used in different countries, in patients with moderate to severe PDB showing normalization of ALP levels in $60 \%$ to $70 \%$ of subjects after a course of treatment, and maintenance of biochemical remission for one year or longer in several patients. ${ }^{40,47}$ Retreatment with both these compounds is generally recommended once normal levels of ALP rise again above normal or when nadir levels (if normal levels are not achieved with the first treatment course) rise by $25 \%$ or more. ${ }^{24}$ The main adverse effects seen with these compounds given as oral regimens were esophageal irritation and upper gastrointestinal discomfort.

Pamidronate disodium has been the first aminobisphosphonate to be used as intravenous regimen in PDB. ${ }^{48}$ Overall, this second generation bisphosphonate, has been found to be safe as well as effective in the treatment of this disorder. Pamidronate requires a 2- to 3-hour prolonged infusion time (30 to $90 \mathrm{mg}$ per infusion) and has been administered in a wide range of dosing schedules, most commonly 60 to $90 \mathrm{mg}$ every 3 months, 6 months or annually. ${ }^{24,49}$ However, optimum dose or number of doses regimens have yet to be defined. The interval between treatment courses widely ranges from 1 month to more than 1 year. ${ }^{49}$ Moreover, one to two doses a week on nonconsecutive days or a dose weekly for 2 to 3 weeks or more have been also used to deliver a total projected dose between 180 and $360 \mathrm{mg}$. Individual response to pamidronate treatment differs based on the extent of disease and activity of the pagetic process. In many cases of moderate to severe disease, three to four 60- to $90-\mathrm{mg}$ doses will bring indices of turnover to normal or near normal, and year-long remissions are not unusual. ${ }^{24}$ Normalization of serum ALP levels is generally seen in up to $50 \%$ of patients, depending on the series and the dose regimens. In studies on patients who had not previously received bisphosphonates, the response could be higher, with biochemical normalization in up to $85 \%$ of PDB patients with moderate disease..$^{50-52}$ Pamidronate therapy has also been reported to improve pagetic pain and overall mobility in symptomatic patients. ${ }^{53-55}$ A study comparing a same total dose of intravenous pamidronate (180 mg for 1 year, given as $30 \mathrm{mg}$ weekly for the first 6 weeks or $45 \mathrm{mg}$ every 3 months) with an higher dose (360 mg for 1 year, given as $30 \mathrm{mg}$ weekly for the first 6 weeks and a further $60 \mathrm{mg}$ weekly for other 3 weeks) demonstrated a dose response effect, with the more severely affected patients requiring a higher total dose for disease suppression. ${ }^{56}$ Other studies confirmed this observation, ${ }^{57-60}$ and higher cumulative dosages of pamidronate have been used in patients with severe PDB, with contrasting results. 
Similar to etidronate and clodronate, reduced effectiveness with repeated treatments (tachyphylaxis or acquired resistance) has also been reported with pamidronate. ${ }^{26,53,61-63}$ In different studies, biochemical relapse was dependent on initial disease severity as assessed by total ALP and on previous bisphosphonate treatment. Importantly, even though some observations have shown an adequate response to high doses of pamidronate in patients thought to be resistant to treatment, ${ }^{62}$ a narrow therapeutic range between resorption inhibition and mineralization defects has been also described for this compound. ${ }^{64-66}$ Cumulative doses of 180 to $360 \mathrm{mg}$ during 6 or 9 weeks have been associated with osteomalacia and increased osteoid thickness on bone biopsy in up to $40 \%$ of patients. ${ }^{64,65}$ Thus, repeated courses with high pamidronate doses over short infusion courses should be administered with caution and cannot be considered as a treatment of choice for long term remission of severe PDB.

Neridronate, or neridronic acid, is an aminohexanebisphosphonate, officially registered in some European countries for the treatment of osteogenesis imperfecta and more recently for PDB. In in vitro studies this compound showed potent inhibition of bone resorption by direct effects on osteoclasts or other bone cells in the immediate microenvironment of the osteoclasts. ${ }^{67}$ Preliminary observation also demonstrated a direct effect of this aminobisphosphonate in enhancing the differentiation of cultured osteoblasts in mature bone-forming cells. ${ }^{68}$ Clinically, neridronate, given as intravenous, intramuscular or oral regimens, has shown remarkable efficacy in different skeletal disorders, including postmenopausal osteoporosis, ${ }^{69}$ osteogenesis imperfecta, ${ }^{70}$ as well as in the suppression of bone turnover in androgen deprivation-treated prostatic carcinoma ${ }^{71}$ or multiple myeloma. ${ }^{72}$ Moreover, this compound has been also used in PDB. Initial studies carried out 20 years ago neridronate, administered either intravenously (mostly $50 \mathrm{mg}$ /day over 4-5 days) or orally (400 mg daily for 1 to 3 months), demonstrated comparable efficacy in suppressing bone turnover markers in patients with PDB. ${ }^{73-76}$ In subsequent short-term studies single intravenous infusions of neridronate were well tolerated and effective in decreasing bone turnover markers in a dose-related manner (from 25 to $200 \mathrm{mg}$ ), in patients with active PDB. ${ }^{77,78}$ The dosage of $200 \mathrm{mg}$ gave consistently good results, even in cases in which the disease was most active leading to normalization of ALP levels in more than $60 \%$ of patients. ${ }^{77,78}$ Moreover, in contrast to pamidronate, no correlation was found between response to treatment and basal bone turnover, and patients who had had significantly higher basal values of bone resorption markers nevertheless had biochemical responses similar to patients with lower values. ${ }^{77}$ A consistent reduction in bone pain at the end of these studies was also registered, and the analgesic effect was usually more pronounced in patients who had entered remission. ${ }^{77}$ Neridronate has also been also successfully used in PDB patients with acquired resistance to either etidronate, clodronate, or pamidronate treatment. ${ }^{63,73,74,77}$ In all the intravenous studies, neridronate infusion was safe and well tolerated, without adverse effects on mineralization nor long-term adverse reactions such as impairment of renal function or hematological abnormalities. A slight, short-lived inflammatory acute phase reaction was observed in $20 \%$ of patients.

The recent development of the newer and more potent intravenous amino-bisphosphonate zoledronic acid has make possible to produce even more profound suppression of disease activity, especially in patients with severe PDB. Zoledronate, or zoledronic acid [1-hydroxy-2(1H-imidazol-1-yl) ethylidene bisphosphonate], is a third-generation imidazole ring containing bisphosphonate. This compound binds strongly to hydroxyapatite ${ }^{79}$ so that it is more likely to be retained in bone during the remodeling cycle because of reattachment of bisphosphonate released during resorption. In addition, its increased potency over the other bisphosphonates in inhibiting osteoclastic bone resorption (through an increased action on the key enzyme farnesyl diphosphate synthase with respect to the other amino bisphosphonates) allows the use of smaller doses to maintain normal bone turnover in a focal area of PDB..$^{80,81}$ Preclinical studies suggested that zoledronate was 100-850 times more potent than pamidronate in vitro and in vivo test systems, and could be administered intravenously for a brief period (15 to 30 minutes) in an ambulatory setting. ${ }^{82}$ Preclinical trials suggested that zoledronic acid is also safer than pamidronate in terms of renal toxicity, and confirmed its improved efficacy in suppressing bone resorption for a sustained period. ${ }^{83,84}$ Moreover, with antiresorptive dose levels in these studies there have been no detectable impairments of either bone formation or mineralization. ${ }^{83,84}$

The first human trial of zoledronate was performed in 16 patients with active PDB in a 2-week study interval. ${ }^{85}$ Different doses of zoledronate $(24,72,216$, and $400 \mu \mathrm{g})$ were infused in $60 \mathrm{ml}$ normal saline over 60 minutes. A significant reduction in bone-resorption markers (24-hour urinary hydroxyproline/creatinine excretion (OHP) and 24-hour urinary calcium/creatinine excretion) was observed with the $216 \mu \mathrm{g}$ and $400 \mu \mathrm{g}$ doses $(20 \%$ to $50 \%$ in the urinary OHP and $40 \%$ to $70 \%$ for urinary calcium/creatinine). Not surprisingly, there 
were no changes in the levels of bone formation markers (total or bone specific ALP). In fact, as has been reported with other bisphosphonates, the initial effect of these compounds is an inhibition of osteoclast-mediated bone resorption; while reductions in the coupled increases in osteoblast-mediated bone formation generally lag behind by several weeks. ${ }^{28}$ Following this preliminary observation a larger dose ranging study was performed over 3 months in 176 PDB patients, randomized to receive a single intravenous infusion with 50 , 100,200 , or $400 \mu \mathrm{g}$ zoledronate. ${ }^{86}$ A dose-response relationship was observed concerning the proportion of responders. The $400 \mu \mathrm{g}$ dose was far superior to $50 \mu \mathrm{g}, 100 \mu \mathrm{g}, 200 \mu \mathrm{g}$, and placebo and was associated with normalization of ALP levels in $20 \%$ and therapeutic response (defined as normalization or at least $50 \%$ reduction in baseline ALP levels following treatment ) in $46 \%$ of patients. It was concluded, however, that the maximum effective dose for PDB was probably not achieved in this trial.

The results from a pivotal double-blinded, randomized clinical study using zoledronic acid in comparison to risedronate in patients with active PDB were released in $2005 .^{87}$ The study design combined two identical, 6-month trials with patients either receiving one iv infusion of zoledronic acid $5 \mathrm{mg}$ over 15 minutes $(\mathrm{n}=177)$ or risedronate $30 \mathrm{mg}$ daily for 2 months $(n=172)$. The primary endpoint was the proportion of patients who achieved a therapeutic response, defined as normalization of ALP or a reduction of at least $75 \%$ from baseline in ALP excess (the difference between the measured level and the midpoint to the reference range) at 6 months. Interestingly, rates of therapeutic response were higher in zoledronate than risedronate at all time-points after 10 days, reaching $96 \%$ for zoledronate and $74 \%$ for risedronate at 6 months. The median time to a first therapeutic response was also significantly lower in the zoledronate (64 days) than risedronate (89 days) group. Normalization rates of alkaline phosphatase also showed differences between groups at all time-points from 1 month onward. At 6 months normalization was observed in $88.6 \%$ of zoledronate treated patients and in $57.9 \%$ of patients in the risedronate group. Moreover, the greater response rates with zoledronate were independent of age, sex, baseline alkaline phosphatase, and previous therapy for PDB. Pain scores improved in both treatment groups, while improvement in quality of life were generally higher with zoledronate than risedronate. It might be argued, however, that the superiority of zoledronic acid observed in this study might be simply a dose-related effect. In fact, considering the differences in potency between the 2 bisphosphonates, risedronate $30 \mathrm{mg} /$ day given for 60 days (for 60 days) cannot be compared with zoledronic acid $5 \mathrm{mg}$ intravenously, because the latter represents a higher effective dose. It is likely that longer courses of oral risedronate could be expected to produce high rates of normalization of bone turnover markers, as well as a longer persistence of the therapeutic effect in this comparative trial with zoledronate. At the same time, a single intravenous administration of zoledronate at longer intervals (probably more than 1 year for most PDB patients) is more likely to be tolerated and to induce a better compliance compared with oral aminobishosphonates that have to be taken daily while fasting and for several months. A follow-up extension trial in 267 patients of the latter study confirmed the increased and sustained efficacy of single zoledronate $5 \mathrm{mg}$ infusion over risedronate, given $30 \mathrm{mg} /$ day for 60 days. ${ }^{88}$ A sustained therapeutic response at 24 months from treatment was noted in $98 \%$ of patients treated with zoledronic acid compared with $57 \%$ of those treated with risedronate. Interestingly, patients treated with risedronate who had experienced prior bisphosphonate therapy seemed more vulnerable to relapse than those who were treatment naive. This trend was not seen in those treated with zoledronate, confirming the efficacy of this compound also in patients who developed a resistance to other bisphosphonate regimens. This latter point has been confirmed and extended in a 15 months study that compared the effects of intravenous infusions of pamidronate, zoledronate and neridronate in 90 subjects with active $\mathrm{PDB} .{ }^{63}$ In the first part of the study, PDB patients were randomly assigned to receive pamidronate $(30 \mathrm{mg}, \mathrm{IV}$, for 2 consecutive days every 3 months; $n=60)$ or zoledronate $(4 \mathrm{mg}$, $\mathrm{n}=30$ ). After 6 months, non-responders to pamidronate were crossed over to zoledronate $4 \mathrm{mg}$ or neridronate (100 mg, for 2 consecutive days) (Figure 2). The primary efficacy endpoint was the same of the previous trial comparing zoledronate to risedronate. At 6 months, $97 \%$ of patients receiving zoledronate had a therapeutic response compared with $45 \%$ of patients receiving pamidronate. Normalization of alkaline phosphatase was achieved in $93 \%$ of patients in the zoledronate group and in $35 \%$ of patients in the pamidronate group and was maintained in $79 \%$ and $65 \%$ of zoledronate-treated patients after 12 and 15 months from infusion. Moreover, both neridronate and zoledronate were able to achieve therapeutic response in $93 \%$ and $94 \%$ of patients that were non-responders to pamidronate after 6 months. Interestingly, all three bisphosphonate regimens were effective in decreasing pain in a consistent group of patients (from 63\% to 76\%), with a slightly increased efficacy of zoledronate and neridronate over pamidronate. Consistent with the previous findings, the response to both neridronate and zoledronate did not seem to 


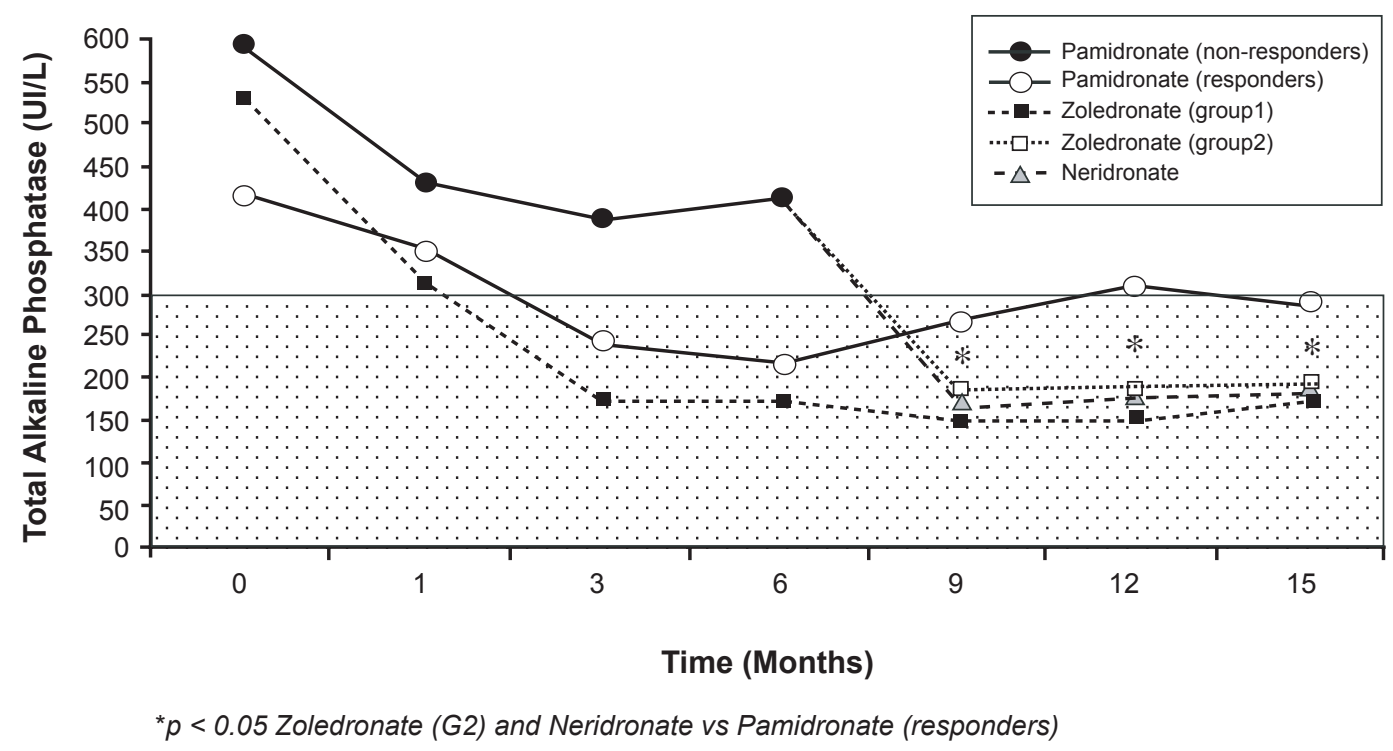

Figure 3 Mean serum alkaline phosphatase (ALP) during a 15-month study comparing intravenous neridronate and zoledronate treatment in Paget's disease of the bone patients resistant to pamidronate. The shaded area represents the normal range of serum ALP. Adapted from J Bone Miner Res. 2007;22:15I0-I5I7,63 with permission of the American Society for Bone and Mineral Research.

be significantly affected by age, number of pagetic skeletal sites, or ALP levels. Overall, the long-term normalization rates of zoledronate observed in this study were lower than in the previous trial, possibly because of the lower zoledronate dose used ( $4 \mathrm{mg}$ instead of $5 \mathrm{mg}$ ). Taken together, these results from long-term comparative studies strongly support the use of single intravenous infusions of zoledronate as a costeffective and, may-be, first-line treatment option in patients with active PDB.

In a preliminary study on 26 patients with active PDB, a single intravenous injection of zoledronate (200 or 400 $\mathrm{mcg}$ ) not only reduced bone turnover but also directly decreased type II collagen degradation (whose expression is restricted to cartilage, not bone), suggesting a potential chondroprotective effect. ${ }^{89}$ These data are consistent with experimental observations (rabbit model of inflammatory arthritis) showing that subcutaneous zoledronate injection partially protects articular cartilage from degradation, ${ }^{90}$ and may provide an additional rationale for the use of zoledronate in PDB, given the increased prevalence of cartilage damage and osteoarthritis described in this disorder.

\section{Tolerability and safety of aminobisphosphonates}

The use of aminobisphosphonates significantly reduced the risk of focal osteomalacia, observed with high dose regimens with previous bisphosphonates such as etidronate and consistently improved patient adherence to treatment. These aminobisphosphonates given either orally or intravenously are generally well tolerated. Oral regimens can be associated with esophageal irritation and upper gastrointestinal discomfort that can be generally more frequent than in oral regimens used to treat osteoporosis due to the cumulative higher dosages. Moreover, patient compliance can be impaired since oral assumption requires to fast before and after treatment because of their very low oral bioavailability and to remain upright for at least 30 minutes after dosing. All these aspects may affect compliance patients, so that oral formulations could be no appropriate for severe forms of PDB, in which a prompt suppression of disease activity is warranted and repeated treatment courses are often required. Intravenous bisphosphonate regimens have partially overcome these problems.

All nitrogen-containing bisphosphonates administered intravenously can induce an acute phase reaction with fever, musculoskeletal pain and other flu-like symptoms which occur after the first dose in approximately 33\% of patients with a decline to approximately $6 \%$ with a second dose and $3 \%$ with a third dose. ${ }^{91}$ These effects are transient and occur predominantly on first exposure to the drug in most patients who has not previously been exposed to a nitrogen-containing bisphosphonate. In fact, previous treatment with a bisphosphonate appears to provide some protection from acute phase reactions with zoledronic acid or other aminobisphosphonates. ${ }^{92}$ This adverse event seems to be related to the accumulation of isopentenyl diphosphate (IPP), the metabolite immediately upstream of farnesyl pyrophosphate (FPP) synthase in the mevalonate pathway by cells (most likely monocytes) in peripheral 
blood, due to the inhibition of FPP synthase by nitrogen bisphosphonates. IPP is known to be a ligand for the most common subset of $\gamma \delta$-T cells in humans, $\mathrm{V} \gamma 9 \mathrm{~V} \delta 2 \mathrm{~T}$ cells. ${ }^{93}$ Although the precise mechanism by which IPP is released or "presented" to these $\gamma \delta$-T cells remains unknown, their activation perhaps via a selective receptor, causes the release of TNF- $\alpha$ and thereby initiates the proinflammatory acutephase response. Interestingly, the activation of $\gamma \delta$-T cells by nitrogen bisphosphonates can be completely overcome in vitro by cotreating cells with statins, which prevent the accumulation of IPP. ${ }^{94}$ Use of acetaminophen or a nonsteroidal anti-inflammatory drug is very helpful in ameliorating the self-limited flu-like symptoms.

Some reports have documented hypocalcemia, especially occurring in patients treated with intravenous amino-bisphosphonates. This complication is generally asymptomatic and mostly occurs if patients do not take their calcium and vitamin D supplements. In trials using the most potent intravenous bisphosphonates, zoledronate, mild hypocalcemia, defined as ionized calcium concentration $<1.21 \mathrm{mM}$ occurred in $2 \%$ to $6 \%$ of patients, while only few cases experienced symptomatic hypocalcemia. ${ }^{63,87}$ Thus, any pre-existing hypocalcemia or condition that may impair calcium balance should be treated before treatment with zoledronic acid or other intravenous aminobisphosphonates.

Intravenous bisphosphonates have been associated with adverse renal effects that are primarily related to dose and infusion time, with the risk increasing with higher dose and faster infusion time, ${ }^{95}$ especially in treating patients with malignant bone disease. To date, no major long-term effects on renal function were reported with pamidronate, neridronate, and zoledronate in PDB patients with normal renal function at baseline. ${ }^{63}$ However, the possibility of renal toxicity of these compounds should be borne in mind. ${ }^{96}$

Osteonecrosis of the jaw (ONJ) has been identified as a potential complication, particularly with long-term, high dose intravenous bisphosphonate therapy in malignant diseases. ${ }^{97}$ This is a rare disorder of the oral cavity that has recently been defined as the presence of exposed bone in the maxillofacial region that does not heal within 8 weeks after identification by a health care provider. ${ }^{98}$ To date, most cases of bisphosphonate-related ONJ (about 94\%) have been reported in patients who receive monthly intravenous bisphosphonates such as pamidronate or zoledronate for the treatment of malignancies, particularly multiple myeloma and metastatic cancer. ${ }^{99}$ Conversely, this complication seems extremely rare in patients with PDB treated with a bisphosphonate. The etiology of ONJ is unknown and relevant prospective clinical trials to study pathogenic mechanisms are not available. Potential risk factors include long duration of exposure to bisphosphonate treatment, glucocorticoid use, recent dental extraction, invasive oral bone surgery, poorly fitting dental appliances and/or intraoral trauma, pre-existing dental or periodontal disease, cancer, anti-cancer therapy, and alcohol/tobacco abuse. ${ }^{98}$ Based on current findings, the risk of ONJ in bisphosphonate-treated patients for osteoporosis or PDB is low (an estimated prevalence of less than one in 100,000 patient-years in noncancer patients), and in these conditions the benefits of therapy generally far outweighs the risk. Thus healthy patients receiving bisphosphonates for PDB do not require any special dental treatment beyond routine care and standard procedures. ${ }^{100}$ It is probably prudent for clinicians to do a routine oral examination before prescribing a bisphosphonate and to consider appropriate preventive dental care prior to treatment in patients with a history of ONJ risk factors.

There have been concerns about whether bone strength is impaired by the use of prolonged high doses of aminobisphosphonates. In particular, some concerns about the consequences of oversuppression of bone turnover from bisphosphonates have been recently raised ${ }^{101,102}$ and a case report of bisphosphonate-induced osteopetrosis was published. ${ }^{103}$ However, there are many animal studies that indicate that bisphosphonates maintain bone strength. Moreover, a recent study looking at comparable dosing of zoledronate vs alendronate in a cohort of patients with osteoporosis did not evidence oversuppression of bone formation or impaired mineralization in biopsies from 23 patients. ${ }^{92}$ To date only few transiliac bone biopsies from sites of PDB after treatment with zoledronate were performed. There was no evidence of adynamic bone or qualitative abnormalities of bone formation in any of these biopsies. ${ }^{104} \mathrm{~A}$ recent study evidenced unusual effects of long term alendronate treatment on bone cells in some patients, namely an increase in the number of osteoclasts including distinctive giant, hypernucleated, detached osteoclasts undergoing protracted apoptosis. ${ }^{105}$ This issue deserves further investigation with the inclusion of the other amino bisphosphonates.

Recent studies had also described additional potential risks related to the use of bisphosphonates such as severe musculoskeletal pain ${ }^{106}$ and a potential relationship to esophageal cancer with oral bisphosphonates use ${ }^{107}$ while others evidenced the lack of any clear relationship to the development of atrial fibrillation. ${ }^{106}$

The safety profile of intravenous zoledronate has been further demonstrated in subjects with postmenopausal 
osteoporosis..$^{91,108}$ Of interest, in these studies, patients treated with zoledronic acid had a $28 \%$ lower risk of allcause mortality than those receiving placebo $(9.6 \%$ vs $13.3 \%, P=0.01)$.

\section{Other treatment options}

Although antiresorptive therapy is highly effective at improving bone pain that is due to increased metabolic activity of the disease, patients with established PDB often have complications such as bone deformity and osteoarthritis which do not respond well to antiresorptive therapy. In these circumstances analgesic drugs and anti-inflammatory drugs are frequently needed for adequate symptom control. ${ }^{109}$ Other nonpharmacological approaches such as acupuncture, physiotherapy, hydrotherapy, and transcutaneous electrical nerve stimulation can also be used for pain control, and specific problems such as limb shortening and deformity can be helped by aids and devices such as walking sticks and shoe raises. The effectiveness of these strategies has not been specifically assessed in patients with Paget's disease of bone, but aids and devices were associated with substantially improved health-related indices of quality of life in participants of the PRISM study. ${ }^{109}$ Sometimes, surgical intervention is required for the management of complications due to PDB. The most common indication for surgical treatment is joint replacement for osteoarthritis, but others include fracture fixation, osteotomy to correct bone deformity, surgery to correct spinal stenosis, and prophylactic surgery in patients with painful pseudofractures. ${ }^{110}$ The operative fixation of pagetic fractures can be technically challenging because of bony enlargement, deformity, hard bone, and increased vascularity, although operative treatment for PDB is generally very useful in improving quality of life for people with the disorder, especially those with advanced osteoarthritis. ${ }^{111}$ Bisphosphonate treatment is frequently given before elective orthopedic surgery to try to reduce operative blood loss, but the effects of bisphosphonate therapy on blood loss have never been studied in a controlled trial. Orthopedic surgery might also be needed in patients who develop osteosarcoma, but the prognosis is poor even with aggressive operative treatment, with an overall 5-year survival of about $6 \%{ }^{112-115}$

\section{Conclusions}

Since the discovery of the profound effects of the bisphosphonates on calcium metabolism, the treatment of PDB has evolved remarkably over the last several decades, from using drugs simply to reduce bone pain to using others designed to induce remission and prevent deformity and possibly other long-term complications. The overall therapeutic utility of a bisphosphonate depends upon the potency of the anti-bone resorbing properties and the dose at which the unwanted impairment of mineralization and osteomalacia occurs. This issue is particularly consistent in the treatment of PDB, where high cumulative doses are often required to achieve normal bone turnover and biochemical remission.

With the development of new intravenous bisphosphonates that have higher potency in farnesyl diphosphate synthase inhibition and longer-term retention in bone, there is now the potential for treating such conditions with intermittent dosing over longer intervals and sustained clinical remission. These approaches also present consistent advantages with regard to patient adherence to treatment.

\section{Disclosures}

The authors declare no conflicts of interest.

\section{References}

1. Paget J. On a form of chronic inflammation of bones (osteitis deformans). Med Chir Trans. 1877;60:37-63.

2. Altman RD. Paget's disease of bone. In Disorders of Bone and Mineral Metabolism. Coe FL, Favus MJ, editors. Raven Press; New York; 1991. p. 1027-1064.

3. Barker DJ. The epidemiology of Paget disease. Metab Bone Dis Relat Res. 1981;3:231-233.

4. Detheridge FM, Guyer PB, Barker DJ. European distribution of Paget's disease of bone. Br Med J. 1982;285:1005-1008.

5. Cooper C, Harvey NC, Dennison EM, van Staa TP. Update on the Epidemiology of Paget's Disease of Bone. $J$ Bone Miner Res. 2006;21:3-8.

6. van Staa TP, Selby P, Leufkens HG, Lyles K, Sprafka JM, Cooper C. Incidence and natural history of Paget disease of bone in England and Wales. J Bone Miner Res. 2002;17:465-471.

7. Barker DJ, Chamberlain AT, Guyer PB, Gardner MJ. Paget disease of bone: the Lancashire focus. Br Med J. 1980;280:1105-1107.

8. Cooper C, Schafheutle K, Dennison E, Kellingray S, Guyer P, Barker D. The epidemiology of Paget disease in Britain: is the prevalence decreasing? J Bone Miner Res. 1999;14:192-197.

9. Cundy T, McAnulty K, Wattie D, Gamble G, Rutland M, Ibbertson HK Evidence for secular change in Paget disease. Bone. 1997;20:69-71.

10. Roodman GD, Windle JJ. Paget's disease of bone. J Clin Invest. 2005;115:200-208.

11. Yip KH, Feng H, Pavlos NJ, Zheng MH, Xu J. p62 ubiquitin bindingassociated domain mediated the receptor activator of nuclear factorkappa B ligand-induced osteoclast formation: a new insight into the pathogenesis of Paget's disease of bone. Am J Pathol. 2006;169: 503-514.

12. Rea SL, Walsh JP, Ward L, et al. A novel mutation (K378X) in the sequestosome 1 gene associated with increased NF-kappa B signalling and Paget's disease of bone with a severe phenotype. $J$ Bone Miner Res. 2006;21:1136-1145.

13. Merlotti D, Gennari L, Galli B, et al. Characteristics and familial aggregation of Paget's disease of bone in Italy. $J$ Bone Miner Res. 2005;20:1356-1364.

14. Poncelet A. The neurologic complications of Paget's disease. J Bone Miner Res. 1999;14:88-91.

15. Ooi CG, Fraser WD. Paget's disease of bone. Postgrad Med. 1997; 73:69-74. 
16. Strickenberger SA, Schulman SP, Hutchins GM. Association of Paget's disease of bone with calcific aortic valve disease. Am J Med. 1987;82:953-956.

17. Huvos AG. Osteogenic sarcoma of bones and soft tissues in older persons. A clinicopathologic analysis of 117 patients older than 60 years. Cancer. 1986;57:1442-1449.

18. Jacobs TP, Michelsen J, Polay JS, D Adamo AC, Canfield RE. Giant cell tumor in Paget's disease of bone: familial and geographic clustering. Cancer. 1979;44:742-747.

19. Siris ES, Feldman F. Natural history of untreated Paget's disease of the tibia. J Bone Miner Res. 1997;12:691-692.

20. Meunier PJ, Vignot E. Therapeutic strategy in Paget disease of bone. Bone. 1995;17:489S-491S.

21. Bickerstaff DR, Douglas DL, Burke PH, O Doherty DP, Kanis JA. Improvement in facial deformity of Paget's disease treated with diphosphonates. J Bone Joint Surg Br. 1990;72:132-136.

22. Murdin LM, Yeoh LH. Hearing loss treated with pamidronate. J R Soc Med. 2005;98:272-274.

23. Selby PL, Davie MWJ, Ralston SH, Stone MD. Guidelines on the management of Paget's disease of bone. Bone. 2002;31:366-373.

24. Siris ES, Lyles KW, Singer FR, Meunier PJ. Medical management of Paget's disease of bone: implications for treatment and review of current therapies. J Bone Miner Res. 2006;21:94-97.

25. Reginster JY, Franchimont P. Side effects of synthetic salmon calcitonin given by intranasal spray compared with intramuscular injection. Clin Exp Rheumatol. 1985;3:155-157.

26. Papapoulos SE, Eekhoff EM, Zwinderman AH. Acquired resistance to bisphosphonates in Paget's disease of bone. J Bone Miner Res. 2006;21:88-91.

27. Russell G. Bisphosphonates from bench to bedside. Ann NY Acad Sci. 2006;1068:367-401.

28. Canfield RE, Rosner W, Skinner J, et al. Diphosphonate therapy of Paget disease of bone. J Clin Endocrinol Metab. 1977;44:96-106.

29. Siris ES, Jacobs TP, Canfield RE. Paget's disease of bone. Bull NY Acad Med. 1980;56:285-304.

30. Siris E, Canfield R, Jacobs T, Stoddart K, Spector T. Clinical and biochemical effects of EHDP in Paget's disease of bone: patterns of response to initial treatment and to long-term therapy. Metab Bone Dis Relat Res. 1981;3:301-308.

31. Roux C, Gennari C, Farrerons J, et al. Comparative prospective, doubleblind, multicenter study of the efficacy of tiludronate and etidronate in the treatment of Paget's disease of bone. Arthritis Rheum. 1995;38:851-885.

32. Delmas PD, Meunier PJ. The management of Paget's disease of bone. N Engl J Med. 1997;336:558-566.

33. McClung MR, Tou CPK, Goldstein NH, Picot C. Tiludronate therapy for Paget's disease of bone. Bone. 1995;17:493S-496S.

34. Plosker GL, Goa KL. Clodronate. A review of its pharmacological properties and therapeutic efficacy in resorptive bone disease. Drugs. 1994;47:945-982.

35. Delmas PD, Chapuy MC, Vignon E, et al. Long term effects of dichloromethylene diphosphonate in Paget's disease of bone. J Clin Endocrinol Metab. 1982;54:837-844.

36. Douglas DL, Duckworth T, Kanis JA, et al. Biochemical and clinical responses to dichloromethylene diphosphonate (CI2MDP) in Paget's disease of bone. Arthritis Rheum. 1980;23:1185-1192.

37. Meunier PJ, Alexaudre C, Edourd C, et al. Effects of disodium dichloromethylene diphosphonate on Paget's disease of bone. Lancet. 1979;2:489-492.

38. Gray RES, Yates APJ, Preston CJ, et al. Duration of effects of oral diphosphonate therapy in Paget's disease of bone. $Q J$ Med. 1987;245:755-767.

39. Khan SA, McCloskey EV, Nakatsuka K, Orgee J, Coombes GM, Kanis JA. Duration of response with oral clodronate in Paget's disease of bone. Bone. 1996;18:185-190.

40. Siris ES, Weinstein RS, Altman R, et al. Comparative study of alendronate vs etidronate for the treatment of Paget disease of bone. J Clin Endocrinol Metab. 1996;81:961-967.
41. Reid I, Nicholson GC, Weinstein RS, et al. Biochemical and radiologic improvement in Paget's disease of bone treated with alendronate: A randomized placebo-controlled trial. Am J Med. 1996;101:341-348.

42. Adami S, Mian M, Gatti P, et al. Effects of two oral doses of alendronate in the treatment of Paget's disease of bone. Bone. 1994;15:415-417.

43. Peter CP, Kindt MV, Majka JA. Comparative study of potential for bisphosphonates to damage gastric mucosa of rats. Dig Dis Sci. 1998;43:1009-1015.

44. Peter CP, Handt LK, Smith SM. Esophageal irritation due to alendronate sodium tablets: possible mechanisms. Dig Dis Sci. 1998;43:1998-2002.

45. Hooper M, Faustino A, Reid IR, et al. Randomized, active-controlled study of once-weekly alendronate $280 \mathrm{mg}$ high dose oral buffered solution for treatment of Paget's disease. Osteoporos Int. 2009;20: 141-150.

46. Miller PD, Adachi JD, Brown JP, et al. Risedronate vs etidronate: Durable remission with only two months of $30 \mathrm{mg}$ risedronate. J Bone Miner Res. 1997;12:S269.

47. Miller PD, Brown JP, Siris ES, Hoseyni MS, Axelrod DW, Bekker PJ. A prospective, multicenter, randomized, double-blind comparison of risedronate and etidronate in the treatment of Paget disease of bone. Am J Med. 1999; 106:513-520.

48. Frijlink WB, Bijvoet OLM, teVelde J, Heynen G. Treatment of Paget disease with 3-amino-1-hydroxypropylidene-1,1-biphosphonate (APD). Lancet. 1979;1:799-803.

49. Walsh JP, Attewell R, Stuckey BGA, et al. Treatment of Paget disease of bone: A survey of clinical practice in Australia. Bone. 2008;42: 1219-1225.

50. Harinck HI, Papapoulos SE, Blanksma HJ, Moolenaar AJ, Vermeij P, Bijvoet OL. Paget's disease of bone: early and late responses to three different modes of treatment with aminohydroxypropylidene bisphosphonate (APD). BMJ. 1987;295:1301-1305.

51. Joshua F, Epstein M, Major G. Bisphosphonate Resistance in Paget's disease of Bone. Arthritis Rheum. 2003;48:2321-2323.

52. Walsh JP, Ward LC, Stewart GO, et al. A randomized clinical trial comparing oral alendronate and intravenous pamidronate for the treatment of Paget disease of bone. Bone. 2004;34:747-754.

53. Wimalawansa SJ, Gunasekara RD. Pamidronate is effective for Paget disease of bone refractory to conventional therapy. Calcif Tissue Int . 1993;53:237-241

54. Gutteridge DH, Retallack RW, Ward LC, Stuckey BG, et al. Clinical, biochemical, hematologic, and radiographic responses in Paget disease following intravenous pamidronate disodium: a 2-year study. Bone. 1996;19:387-394

55. Trombetti A, Arlot M, Thevenon J, Uebelhart B, Meunier PJ. Effect of multiple intravenous pamidronate courses in Paget disease of bone. Rev Rhum. 1999;66:467-476.

56. Gallacher SJ, Boyce BF, Patel U, Jenkins A, Ralston SH, Boyle IT. Clinical experience with pamidronate in the treatment of Paget disease of bone. Ann Rheum Dis. 1991;50:930-933.

57. Stone MD, Hawthorne AB, Kerr D, Webster G, Hosking DJ. Treatment of Paget disease with intermittent low-dose infusions of disodium pamidronate (APD). J Bone Miner Res. 1990;5:1231-1235.

58. Bombassei GJ, Yocono M, Raisz LG. Effects of intravenous pamidronate therapy on Paget disease of bone. Am J Med Sci. 1994;308:226-233.

59. Stuckey BG, Gutteridge DH, Stewart GO, et al. Intravenous pamidronate in Paget disease - response is dependent on radiographic and biochemical severity. Semin Arthritis Rheum. 1994;23:286.

60. Cundy T, Wattie D, King AR. High-dose pamidronate in the management of resistant Paget disease. Calcif Tissue Int. 1996;58:6-8.

61. Gutteridge DH, Ward LC, Stewart GO, et al. Paget's disease: acquired resistance to one aminobisphosphonate with retained response to another. J Bone Miner Res. 1999;14:79-84.

62. Lyles KW. What is "resistance" in Paget disease of bone? Arthritis Rheum. 2003;48:2097-2099.

63. Merlotti D, Gennari L, Martini G, et al. Comparison of different intravenous bisphosphonate regimens for Paget's disease of bone. $J$ Bone Miner Res. 2007;22:1510-1517. 
64. Adamson BB, Gallacher SJ, Byars J, Ralston SH, Boyle IT, Boyce BF. Mineralization defects with pamidronate therapy for Paget's disease. Lancet. 1993;342:1459-1460.

65. Boyce BF, Adamson BB, Gallacher SJ, Byars J, Ralston SH, Boyle IT. Mineralization defects after pamidronate for Paget disease. Lancet. 1994;343;1231-1232.

66. Buckler HM, Mercer SJ, Davison CE, Hollis S, Richardson PC, Anderson DG. Evaluation of adverse experiences related to pamidronate infusion in Paget disease of bone. Ann Rheum Dis. 1998;57:572.

67. Nicolin V, Bareggi R, Baldini G, Bortul R, Martinelli B, Narducci P Effects of neridronic acid on osteoclasts derived by physiological dual-cell cultures. Acta Histochem. 2007;109:397-402.

68. Spreafico A, Frediani B, Capperucci C, et al. Anabolic effects and inhibition of interleukin 6 production induced by neridronate on human osteoblasts. Reumatismo. 2006;58:288-300.

69. Braga V, Gatti D, Colapietro F, et al. Intravenous intermittent neridronate in the treatment of postmenopausal osteoporosis. Bone. 2003;33:342-345.

70. D’Eufemia P, Finocchiaro R, Celli M, et al. High levels of serum prostaglandin e 2 in children with osteogenesis imperfecta are reduced by neridronate treatment. Pediatr Res. 2008;63:203-206.

71. Magno C, Inastasi G, Morabito N, et al. Preventing bone loss during androgen deprivation therapy for prostate cancer: early experience with neridronate. Eur Urol. 2005;47:575-581.

72. Pittari G, Costi D, Raballo M, Maulucci L, Baroni MC, Mangoni M. Intravenous neridronate for skeletal damage treatment in patients with multiple myeloma. Acta Biomed. 2006;77:81-84.

73. Atkins RM, Yates AJ, Gray RE, et al. Aminohexane disphosphonate in the treatment of Paget disease of bone. J Bone Miner Res. 1987;2: 273-279

74. Delmas P, Chapuy MC, Edouard C, Meunier PJ. Beneficial effects of aminohexane bisphosphonate in patients with Paget disease of bone resistant to sodium etidronate. Am J Med. 1987;83:276-282.

75. McCloskey EV, Yates AJP, Beneton MNC, Galloway G, Harris S, Kanis JA. Comparative effects of intravenous diphosphonates on calcium and skeletal metabolism in man. Bone. 1987;8:S35-S41.

76. Coulton LA, Preston CJ, Couch M, Kanis JA. An evaluation of serum osteocalcin in Paget disease of bone and its response to diphosphonate treatment. Arthrit Rheum. 1988;31:1142-1147.

77. Filipponi P, Cristallini S, Policani G, Casciari C, Gregorio F. Paget disease of bone: benefits of neridronate as a first treatment and in cases of relapse after clodronate. Bone. 1998;23:543-548.

78. Adami S, Bevilacqua M, Broggini M, et al. Short-term intravenous therapy with Neridronate in Paget's disease. Clin Exp Rheumatol. 2002;20:55-58.

79. Nancollas GH, Tang R, Phipps RJ, et al. Novel insights into actions of bisphosphonates on bone: Differences in interactions with hydroxyapatite. Bone. 2006;38:617-627.

80. Dunford JE, Thompson K, Coxon FP, et al. Structure-activity relationships for inhibition of farnesyl diphosphate synthase in vitro and inhibition of bone resorption in vivo by nitrogen containing bisphosphonates. J Pharmacol Exp Ther. 2001;296:235-242.

81. Green JR, Rogers MJ. Pharmacologic profile of zoledronic acid: A highly potent inhibitor of bone resorption. Drug Dev Res. 2002;55:210-224.

82. Body JJ. Clinical research update: zoledronate. Cancer. 1997;80: 1699-1701.

83. Green JR, Muller K, Jaeggi KA. Preclinical pharmacology of CGP 42446, a new, potent, heterocyclic bisphosphonate compound. J Bone Miner Res. 1994;9:745-751

84. Green JR, Seltenmeyer Y, Jaeggi KA, Widler L. Renal tolerability profile of novel, potent bisphosphonates in two short-term rat models. Pharmacol Toxicol. 1997;80:225-230.

85. Arden-Cordone M, Siris ES, Lyles KW, et al. Antiresorptive effect of a single infusion of microgram quantities of zoledronate in Paget disease of bone. Calcif Tissue Int. 1997;60:415-418.

86. Buckler H, Fraser W, Hosking D, et al. Single infusion of zoledronate in Paget disease of bone: a placebo-controlled, dose-ranging study. Bone. 1999;24:81S-85S.
87. Reid IR, Miller P, Lyles K, et al. Comparison of a single infusion of zoledronic acid with risedronate for Paget disease. $N$ Engl J Med. 2005;353:898-908.

88. Hosking D, Lyles K, Brown JP, et al. Long-term control of bone turnover in Paget disease with zoledronic acid and risedronate. $J$ Bone Miner Res. 2007;22:142-148.

89. Garnero P, Christgau S, Delmas PD. The bisphosphonate zoledronate decreases type II collagen breakdown in patients with Paget disease of bone. Bone. 2001;28:461-464.

90. Podworny NV, Kandel RA, Renlund RC, Grynpas MD. Partial chondroprotective effect of zoledronate in a rabbit model of inflammatory arthritis. J Rheumatol. 1999;26:1972-1982.

91. Black DM, Delmas PD, Eastell R, et al. Once-yearly zoledronic acid for treatment of postmenopausal osteoporosis. $N$ Engl J Med. 2007:356:1809-1822.

92. McClung M, Recker R, Miller P, et al. Intravenous zoledronic acid $5 \mathrm{mg}$ in the treatment of postmenopausal women with low bone density previously treated with alendronate. Bone. 2007;41:122-128.

93. Thompson K, Rogers MJ. Bisphosphonates and $\gamma, \delta$ T-cells: new insights into old drugs. BoneKEy-Osteovision. 2006;3:5-13.

94. Thompson K, Rogers MJ. Statins prevent bisphosphonate-induced gamma-delta-T-cell proliferation and activation in vitro. J Bone Miner Res. 2004;19:278-288.

95. Lewiecki EM, Miller PD. Renal safety of intravenous bisphosphonates in the treatment of osteoporosis. Expert Opin Drug Saf. 2007; 6:663-672.

96. Markowitz GS, Fine PL, Stack JI, et al. Toxic acute tubular necrosis following treatment with zoledronate (Zometa). Kidney Int. 2003;64:281-289.

97. Maerevoet M, Martin C, Duck L. Osteonecrosis of the jaw and bisphosphonates. N Engl J Med. 2005;353:99-102.

98. Khosla S, Burr D, Cauley J, et al. Bisphosphonate-Associated Osteonecrosis of the Jaw: Report of a Task Force of the American Society for Bone and Mineral Research. J Bone Miner Res. 2007;22: 1479-1489.

99. Woo SB, Hellstein JW, Kalmar JR. Narrative review: bisphosphonates and osteonecrosis of the jaws. Ann Intern Med. 2006;144:753-761.

100. Grbic JT, Landesberg R, Lin SQ, et al. Incidence of osteonecrosis of the jaw in women with postmenopausal osteoporosis in the health outcomes and reduced incidence with zoledronic acid once yearly pivotal fracture trial. J Am Dent Assoc. 2008;139:32-40.

101. Ott SM. Ten years of alendronate treatment for osteoporosis in postmenopausal women. $N$ Engl J Med. 2004;351:190-192.

102. Odvina CV, Zerwekh JE, Rao DS, Maalouf N, Gottschalk FA, Pak CY. Severely suppressed bone turnover: a potential complication of alendronate therapy. J Clin Endocrinol Metab. 2005;90:1294-1301.

103. Whyte MP, Wenkert D, Clements KL, McAlister WH, Mumm S. Bisphosphonate-induced osteopetrosis. N Engl J Med. 2003;349: 457-463.

104. Reid IR. Zoledronate: Efficacy and Safety. J Bone Miner Res. 2006;21:83-87.

105. Weinstein RS, Roberson PK, Manolagas SC. Giant osteoclast formation and long-term oral bisphosphonate therapy. $N$ Engl $J$ Med. 2009;360:53-62.

106. Recker RR, Lewiecki EM, Miller PD, Reiffel J. Safety of bisphosphonates in the treatment of osteoporosis. Am J Med. 2009;122: S22-S32.

107. Wysowski DK. Reports of esophageal cancer with oral bisphosphonate use. N Engl J Med. 2009;360:89-90.

108. Lyles KW, Colón-Emeric CS, Magaziner JS, et al. Zoledronic acid and clinical fractures and mortality after hip fracture. $N$ Engl J Med. 2007;357:1799-1809.

109. Langston AL, Campbell MK, Fraser WD, Maclennan G, Selby P, Ralston SH. Clinical determinants of quality of life in Paget's disease of bone. Calcif Tissue Int. 2007;80:1-9.

110. Redden JF, Dixon J, Vennart W, Hosking DJ. Management of fissure fractures in Paget's disease. Int Orthop. 1981;5:103-106. 
111. Kaplan FS. Surgical management of Paget's disease. J Bone Miner Res. 1999;14:34-38.

112. Sharma H, MacDu. E, Jane MJ, Reid R. Sarcomatous change in the Pagetoid tibiae. Int Orthop. 2005;29:319-325.

113. Mankin HJ, Hornicek FJ. Paget's sarcoma: a historical and outcome review. Clin Orthop Relat Res. 2005;438:97-102.
114. Mayilvahanan N, Bose JC, Paraskumar M, et al. Paget's sarcoma: limb salvage by custom mega prosthesis: four case reports. J Orthop Surg (Hong Kong). 2004;12:243-247.

115. Devogelaer JP, Bergmann P, Body JJ, et al. Management of patients with Paget's disease: a consensus document of the Belgian Bone Club. Osteoporos Int. 2008;19:1109-1117.

\section{Publish your work in this journal}

Open Access Rheumatology Research and Reviews is an international, peer-reviewed, open access journal, publishing all aspects of clinical and experimental rheumatology in the clinic and laboratory including the following topics: Pathology, pathophysiology of rheumatological diseases; Investigation, treatment and management of rheumatological diseases; Clinical trials and novel pharmacological approaches for the treatment of rheumatological disorders. The manuscript management system is completely online and includes a very quick and fair peerreview system, which is all easy to use. Visit http://www.dovepress.com/ testimonials.php to read real quotes from published authors. 